\title{
OUTCOME OF ACUTE PERITONEAL DIALYSIS (APD) IN RENAL FAILURE AMONG CHILDREN ADMITTED AT CHILDREN'S HOSPITAL AND INSTITUTE OF CHILD HEALTH, MULTAN.
}

1. MBBS,

FCPS (Paediatrics Medicine),

Senior Registrar Paeds Medicine

The Children's Hospital and

The Institute of Child Health, Multan.

2. MBBS, FCPS (Peads Medicine)

Senior Registrar Pediatric Medicine Nishtar Hospital Multan.

3. MBBS, FCPS (Paeds Medicine)

Associate Professor Pediatric

Medicine

Nishtar Hospital, Multan.

Correspondence Address:

Dr. Saima Jabeen Joiya

Department of Pediatric Medicine

Nishtar Hospital Multan

zahidahmad78@gmail.com

Article received on:

09/07/2019

Accepted for publication:

$28 / 10 / 2019$

\begin{abstract}
Shahid Ishaq ${ }^{1}$, Saima Jabeen Joiya², Muhammad Azam Khan ${ }^{3}$
\end{abstract}
\begin{abstract}
Objectives: Renal failure (RF) is associated with significant mortality and morbidity. its management still remains challenging for treating physicians. Acute peritoneal dialysis (APD) is an option for treatment of renal failure among young children. We aimed to determine the efficacy of peritoneal dialysis (PD) in RF among children admitted. Study Design: Case series study. Setting: Nephrology Department of Children's Hospital and Institute of Child Health, Multan. Period: February 2018 to July 2018. Material \& Methods: A total of 74 children with renal failure were included. All the patients were treated with acute peritoneal dialysis. The outcome of interest was clinical and biochemical improvement. Result: Amongst all there were $46(62.2 \%)$ male and $26(37.8 \%)$ female. Mean age of the children was found to be 57.72 months. Mean weight of children was $12.36 \mathrm{~kg}$ with a standard deviation of $6.4 \mathrm{~kg}$. Most of the children, 43 (58.1\%) had acute renal failure (ARF) whereas 31 (41.9\%) had chronic renal failure (CRF). With PD, mortality was reported in 22 (29.7\%) children. Conclusion: Acute peritoneal dialysis showed good rates of improvement in renal function, so, it should be recommending among children with acute renal failure.
\end{abstract}

Key words: $\quad$ Acute Peritoneal Dialysis, Improvement, Mortality, Renal Failure.

Article Citation: Ishaq S, Joiya SJ, Khan MA. Outcome of acute peritoneal dialysis (APD) in renal failure among children admitted at Children's Hospital and Institute of Child Health, Multan. Professional Med J 2020; 27(8):1560-1564.

DOI: 10.29309/TPMJ/2020.27.08.3922

\section{INTRODUCTION}

RF is known to be one of the most important causes of morbidity as well as mortality in children. ${ }^{1}$ Acute decline related to renal functions depicted as raised blood urea nitrogen (BUN) and serum creatinine is described as acute renal failure (ARF). ARF is commonly accompanied by hyperkalemia, metabolic acidosis and hypertension. ${ }^{2,3}$

Early recognition of RF are often delayed and patients come in terminal stages wit dyspnea, oliguria, hypertension and alerted consciousness. It is estimated that over $90 \%$ of the chronic kidney dialysis stage 5 patients cannot afford longterms renal replacement therapy and die within weeks to months of diagnosis. ${ }^{4,5}$ Some causes of ARF like rapidly progressive glomerulonephritis (RPGN) may be presented as acute kidney injury (AKI) which speedily progress in chronic kidney disease. ${ }^{6-8}$ Management options are limited when patient develop ARF and mainstay is mostly dependent on renal replacement therapy (RRT). Timely referral as well as on time start of renal services and timely initiation of RRT as per the physician's choice can improve the outcome in such cases. ${ }^{9-10}$

Peritoneal dialysis provides a fair renal replacement in both acute and acute on chronic renal failure; especially in children where it is easier and more compatible. It is a well know modality. There are different types of peritoneal dialysis and acute peritoneal dialysis. ${ }^{11}$

In a study done at Children Hospital and Institute of Child Health, Lahore, $75 \%$ patients improved clinically and biochemically after peritoneal dialysis. ${ }^{11}$ No study has been conducted in our setting analyzing the efficacy of peritoneal dialysis in children reporting with renal failure. Peritoneal dialysis not only presents opportunities to improve 
the manifestations of renal compromise but also provided time-bridge for future management in chronic renal failure; this is why this study was carried out to evaluate the effectiveness of peritoneal dialysis in children with renal failure at the Children Hospital and the Institute of Child Health, Multan. This would be helpful in formulating in the management protocol for such patients.

\section{MATERIAL \& METHODS}

This case series study was conducted at the Nephrology department of children's hospital and institute of child health, Multan, from February 2018 to July 2018. During the study period, a total of 74 children with acute or chronic renal failure, aged up to 15 years, in which PD was to be performed, were included in this study.

Renal failure was diagnosed according to clinical presentation as well as laboratory findings. Informed consent was sought from the parents or guardians of all the study participants. Demographic information of the patients like age, gender and socio-economic status of the cases were recorded. Detailed history and physical examination was in all evaluating signs of renal failure. Laboratory investigations like complete blood counts, serum electrolytes, renal function tests (RFTs), arterial blood gases (ABGs), prothrombin time, activated partial thromboplastin time, urine complete examination and abdominal ultrasound was don in all the children. Indications regarding PD were recorded.

APD was done employing per cutaneous peritoneal dialysis catheter. Isotonic/hypertonic peritoneal dialysis solutions were utilized. All the children were observed up to 1 week while complications as well as RFTs and ABGs were recorded in this period.

SPSS version 21.0 was used for data analysis. Qualitative variables like gender, complications and outcome were presented as percentages and frequencies. The efficacy was evaluated in terms of improvement in the clinical signs, RFTs and ABGs. Mean and standard deviation were calculated for quantitative variables like, age, number of days of PD and duration of hospital stay. Chi square was test for qualitative while independent sample t-test was used for quantitative variables taking $p$ value less than or equal to 0.05 as significant.

\section{RESULTS}

Amongst all 74 children, there were 46 (62.2\%) male and $26(37.8 \%)$ female. Mean age of the children was found to be 57.72 months. Mean weight of children was $12.36 \mathrm{~kg}$ with a standard deviation of $6.4 \mathrm{~kg}$. Most of the children, 43 $(58.1 \%)$ were noted having ARF whereas 31 (41.9\%) had CRF.

Hemolytic uremic syndrome was noted to be commonest amongst children with ARF while posterior urethral valves were noted to be most predominant amongst children with CRF. Commonest sign in with ARF was noted to be acidotic breathing whereas pallor and fluid overload were noted to be commonest amongst children with CRF. Dysnea was found to be the commonest symptom of ARF while decreased urine output was seen in children with CRF.

Metabolic acidosis was noted as the commonest indication of PD, found in 62 (83.8\%) followed by uremic encephalopathy 24 (32.4\%).

Mean duration of PD was recorded as 4.04 days with a standard deviation of 0.83 days. Mean duration of PD in ARF cases was noted to be 3.91 days with a standard devotion of 0.76 days while it was 4.23 days in children having CRF with standard deviation of 0.97 days ( $p$ value $=$ $0.1161)$.

Complications were reported in 47 (63.5\%) children. Most common complication was recorded to be peritonitis in 13 (17.6\%), followed by catheter leakage 12 (16.2\%) and catheter blockage 10 (13.5\%). Table-I lists data about complications and its distribution in terms of ARF and CRF showing there was no statistical difference between the two in terms of complications ( $p$ value $=0.661$ ). Mean duration of hospital stay was recorded to be 12.73 days with a standard deviation of 3.87 days. All RFTs 
improved with PD. With PD, improvement was noted in 52 (71.6\%) children while 22 (28.4\%) children died.

Mortality was reported in $22(29.7 \%)$ children whereas significantly poor outcome was reported in children with ARF in comparison to children with CRF as shown in Table-II ( $p$ value $=0.0001$ )

\begin{tabular}{|c|c|c|c|c|c|}
\hline Complications & \multicolumn{2}{|c|}{ No. of Children } & \multicolumn{2}{|c|}{ ARF } & CRF \\
\hline Peritonitis & \multicolumn{2}{|c|}{$13(17.6 \%)$} & \multicolumn{2}{|c|}{5} & 8 \\
\hline Catheter Leakage & \multicolumn{2}{|c|}{$12(16.2 \%)$} & \multicolumn{2}{|c|}{7} & 5 \\
\hline Catheter Blockage & \multicolumn{2}{|c|}{$10(13.5 \%)$} & \multicolumn{2}{|c|}{4} & 6 \\
\hline Bleeding & \multicolumn{2}{|c|}{$6(8.1 \%)$} & \multicolumn{2}{|c|}{3} & 3 \\
\hline Wound Infection & \multicolumn{2}{|c|}{$5(6.8 \%)$} & \multicolumn{2}{|c|}{1} & 4 \\
\hline Perforation & \multicolumn{2}{|c|}{1 (1.4\%) } & \multicolumn{2}{|c|}{0} & 1 \\
\hline \multicolumn{6}{|c|}{$\begin{array}{l}\text { Table-I. Complications of PD amongst children with } \\
\qquad \begin{array}{l}\text { RF }(n=47) \\
\text { P value }=0.661\end{array}\end{array}$} \\
\hline Outcome & ARF & CRF & & & Total \\
\hline $\begin{array}{l}\text { Good Response } \\
\text { / Survived }\end{array}$ & $23(53.5 \%)$ & $29(93$ & & 52 & $(70.3 \%)$ \\
\hline Death & 20 (46.5\%) & $2(6.5 \%$ & & 22 & (29.7\%) \\
\hline Total & 43 & 31 & & 74 & \\
\hline
\end{tabular}

\section{DISCUSSION}

Both ARF and CRF require supportive care along with renal replacement therapy. PD is the most commonly used entity in pediatric population. Dialysis programs are flourishing at rates of more than $10 \%$ annually in many Asian countries and PD has been shown to be well suited to our region's population. ${ }^{12,13}$

In the present study, a predominant population of male children as $62.2 \%$ was noted. This was very similar to what other local studies done by Ali A, et $\mathrm{al}^{14}$ and Jamal $\mathrm{A}$, et $\mathrm{al}{ }^{15}$ found.

We noted the mean age of the children to be 57.72 months. A recent study from Children's Hospital and Institute of Child Health, Lahore ${ }^{11}$ noted the mean age of children at the time of presentation as 4.96 years which is very similar to our results. Our results are also consistent with what was found by Jamal $A$, et al. ${ }^{15}$
In the current study, most of the children, 58.1\% were found to have ARF while remaining 41.9\% had CRF. Faraz A, et al in $2017^{11}$ noted $55 \%$ children undergoing PD to be having ARF while $45 \%$ had CRF which is very close to our findings. Saeed $A$, et al in $2005^{16}$ analyzing children undergoing PD, recorded $74 \%$ children having ARF while $26 \%$ had CRF. More children noted having ARF could be due to increased awareness of PD regarding ARF and selection of hemodialysis for most cases having CRF. ${ }^{11}$

Present work showed that most children having RF presented having vomiting, altered consciousness, acidotic breathing and pallor. These are the most common form of presentations noted by other researchers as well. ${ }^{11}$ We noted pallor and fluid overload as commonest amongst children with CRF while another study noted that children having CRF presented with growth failure, metabolic acidosis and hypertension. ${ }^{17}$

In this study, commonest cause of children with ARF was found to be haemolytic uremic syndrome which is quite similar to what has been found earlier by other local studies. ${ }^{11,15}$ Posterior urethral valves was noted to be the commonest cause of CRF which is again very similar to some other findings from local researchers. ${ }^{16,17}$ Diabetes and hypertension has also been noted to be commonest causes of CRF in a general population study. ${ }^{18}$

We recorded mean duration of PD as 4.04 days which is quite near to what has been found from other parts of Pakistan like 3.85 days ${ }^{11}$ and 4.12 days ${ }^{15}$ by other researchers.

Peritonitis is known to be a commonest complication of PD in many national ${ }^{14,16}$ and international studies. ${ }^{19,20}$ Catheter related complications are also very common in children undergoing PD. ${ }^{11,15}$ Higher rates of peritonitis in comparison to present work have also been reported earlier. ${ }^{16}$ Peritonitis has been linked with technique as well as upholding asepsis conditions. ${ }^{11}$

Mortality was noted in 29.7 of children in our 
study. Another study done in Lahore, Pakistan ${ }^{11}$ noted overall mortality of $23 \%$ whereas other works have seen it to be $24 \%{ }^{16}$ and $17 \% .{ }^{1}$ Slightly higher rates of mortality in the present findings could be because many of the children enrolled with ARF had poor outcome expected.

\section{CONCLUSION}

Acute peritoneal dialysis showed good outcome and overall improvement in renal functions. APD should be recommending among children with acute renal failure. APD is linked with complications but its benefits outweigh complications associated with it.

Copyright@ 28 Oct, 2019.

\section{REFERENCES}

1. Jamal A, Ramzan A. An experience of renal replacement therapy in children. $J$ Coll Physicians Surg Pak 2002; 12:43-7.

2. Hassan KI Hodan JM, Chunfu L. A retrospective study of acute renal failure in children: Its incidence, etiology, complications and prognosis monitoring. Cureus. 2017 May; 9(5): e1274.

3. Bunchman TE, McBryde KD, Mottes TE, Gardner JJ, Maxvold NJ, Brophy PD. Pediatric acute renal failure: Outcome by modality and disease. Pediatr Nephrol. 2001, 16:1067-1071.

4. Anochie I, Eke F. Chronic renal failure in children: A report from Port Harcourt, Nigeria (1985-2000) Pediatr Nephrol. 2003; 18(7):692-695.

5. Arogundade F, Sanusi A, Okunola O, Soyinka F, Ojo O, Akinsola A. Acute renal failure (ARF) in developing countries: Which factors actually influence survival. The Central African journal of medicine. 2006; 53(58):34-39.

6. Kandoth PW, Agarwal GJ, Dharnidharka VR. Acute renal failure in children requiring dialysis therapy. Indian Pediatr. 1994, 31:305-309.

7. Barletta GM, Bunchman TE. Acute renal failure in children and infants. Curr Opin Crit Care. 2004, 10:499504.

8. Choudhry VP, Srivastava RN, Vellodi A, et al. A study of acute renal failure. Indian Pediatr. 1980, 17:405-410.
9. Shaheen IS, Watson AR, Harvey B: Acute renal failure in children: etiology, treatment and outcome. Saudi J Kidney Dis Transpl. 2006, 17:153-158.

10. Halle HP, Lapsap CT, Barla E, Fouda H, Djantio H, Moudze BK, et al. Epidemiology and outcomes of children with renal failure in the pediatric ward of a tertiary hospital in Cameroon. BMC Pediatr. 2017; 17: 202.

11. Faraz A, Farhan MA, Shaikh K, Ali S. Experience of peritoneal dialysis in renal failure in children. Pak Armed Forces Med J 2017; 67 (6): 1015-21.

12. Lee G. End-stage renal disease in the Asian-Pacific region. Semin Nephrol 2003; 23: 107-14.

13. Li PK, Lui SL, Leung CB, Yu AW, Lee E, Just PM, et al. Increased utilization of peritoneal dialysis to cope with mounting demand for renal replacement therapy- perspectives from Asian countries. Perit Dial Int 2007; 27: 59-61.

14. Ali A, Muhammad N, Akhtar SZ, Khan MD, Noman M. Paediatric acute renal failure in frontier province. $J$ Postgrad Medlnst 2004; 18: 308-15.

15. Jamal A, Ramzan A. Renal and post-renal causes of acute renal failure in children. $J$ Coll Physicians Surg Pak 2004; 14:411-5.

16. Saeed A, Yaqoob M, Masood MK, Hafeez F, Izhar TS, Atta Ullah. Peritoneal dialysis; Indication, efficacy and acute complications. Pak Paed J 2005; 29: 121-8.

17. Hafeez F, Yaqoob M, Bano I, Maqbool S. Chronic renal failure in children. J Coll Physicians Surg Pak 2002; 12: $154-56$.

18. Kazancioğlu R. Risk factors for chronic kidney disease: An update. Kidney Int Suppl 2013; 3: 368-71.

19. Fraser N, Hussain FK, Connell R, Shenoy MU. Chronic peritoneal dialysis in children. Int $\mathrm{J} \mathrm{Nephrol} \mathrm{Renovasc}$ Dis 2015; 8: 125-37.

20. Warady BA, Bakkaloglu S, Newland J, Cantwell M, Verrina $E$, Neu A, et al. Consensus guidelines for the prevention and treatment of catheter-related infections and peritonitis in pediatric patients receiving peritoneal dialysis: 2012 Update. Perit Dial Int 2012; 32: S32-S86. 


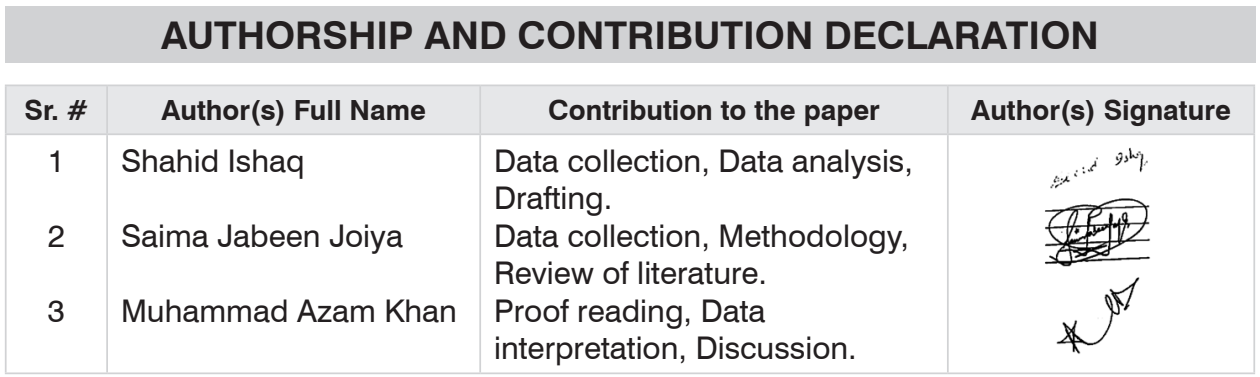

